\title{
Extent of Resection
}

National Cancer Institute

\section{Source}

National Cancer Institute. Extent of Resection. NCI Thesaurus. Code C157443.

The degree to which the lesion has been cut out, or resected. 